\title{
ERINNERUNG ALS KULTUR, KULTUREN DES ERINNERNS - INITIATIVEN ZUM GEDENKEN IM AUSGANG DEUTSCH, TSCHECHISCHER UND POLNISCHER DEBATTEN
}

\author{
TOMASZ DZIURA (WROC $Ł A W)$
}

\begin{abstract}
MEMORY AS CULTURE, CULTURES OF REMEMBRANCE ON COMMEMORATION INITIATIVES STARTING FROM GERMAN, CZECH AND POLISH DEBATES
\end{abstract}

In the perspective of the concept of the "site of memory", this paper discusses how the projects planned in Germany to commemorate flight and expulsion of the Germans after World War 2 and other forced migration processes in Europe within the 20th century were received in Czech Republic, Poland and Germany. This debate begun at the end of the 20th century, after the Federation of Expellees had announced their plans to establish the Centre against Expulsions. In context of this debate other issues were carried out, e.g. property claims, which were more observable in Czech Republic due to the last phase of the negotiation connected with the European Union accession. On the other hand, the debate in Poland and Germany, regarded rather moral than political aspects, but the most controversial point was an argument about Erika Steinbach, chairwoman of the Federation of Expellees. In Germany the debate became controversial, as the left-wing parties put through the idea of a European Centre in cooperation with East European Countries involved in flight and expulsions, as the right-wing parties insisted on establishing a German Centre in Berlin. After the elections in 2005 and after building the great coalition (CDU and SPD) the parties came to an agreement and decided to build the Museum of Expulsions in Berlin. After the resignation of Erika Steinbach in 2009, the Polish government stopped opposing. The author confronts the history of these planned memorials with the concept of the so-called "sites of memory" by Pierre Nora and others.

Key words: cultural memory, site of memory, expulsion, Poland, Czech Republic, Germany

\section{ABSTRAKT \\ PAMĚŤ JAKO KULTURA, KULTURY VZPOMÍNÁNÍ - INICIATIVY PŘIPOMÍNÁNÍ V ZRCADLE NĚMECKÝCH, ČESKÝCH A POLSKÝCH DEBAT}

Článek se zabývá historií plánovaných památníků věnovaných uprchlictví a vyhánění Němců po druhé světové válce a dalším procesům nucené 
migrace v Evropě v průběhu 20. století a jejich přijetím v České republice, Polsku a Německu. Tato debata začala na konci 20. století poté, co Svaz vyhnanců oznámil své plány založit Centrum proti vyhánění. V souvislosti s touto debatou byly oživeny další otázky, např. majetkové nároky, jejichž tematizace byla v České republice zřetelná zejména v poslední fázi vyjednávání o přistoupení k Evropské unii. Debaty v Polsku a Německu se odehrávaly spíše na morální než politické rovině, nejkontroverznějším bodem však byly spory o Eriku Steinbachovou, předsedkyni Svazu vyhnanců. Napětí do debat v Německu vnesl nesoulad mezi levicovými stranami, jež prosazovaly myšlenku evropského centra ve spolupráci s východoevropskými zeměmi spojenými s dějinami vyhánění, zatímco pravicové strany trvaly na založení německého centra v Berlíně. Po volbách v roce 2005 a ustavení velké koalice CDU a SPD padlo rozhodnutí vybudovat muzeum vyhánění v Berlíně. Po odstoupení Erika Steinbachové v roce 2009 projekt akceptovala i polská vláda. Autor konfrontuje dějiny těchto plánovaných památníků s konceptem tzv. „míst paměti“ Pierra Nory a dalších.

Klíčová slova: kulturní pamět, místa paměti, vyhnání, Polsko, Česko, Německo

\section{Einleitung}

Seit geraumer Zeit sind Erinnerungsorte ein wichtiger Bestandteil des kollektiven Gedächtnisses vieler Staaten. Konzeptionell geht der Begriff, Erinnerungsort' (frz. le lieux de memoire) auf den französischen Historiker Pierre Nora zurück. ${ }^{1}$ In seinem gleichnamigen Hauptwerk stellte er, zusammen mit vielen anderen Autoren, die wichtigsten Erinnerungsorte Frankreichs vor. In Anlehnung an Pierre Nora wurde in Deutschland ein ähnliches Projekt durchgeführt, dessen Ergebnis das der deutschen Geschichte gewidmete dreibändige Werk Deutsche Erinnerungsorte ist (vgl. François 2005: 8), das wiederum die wichtigsten deutschen Erinnerungsorte, darunter auch Flucht und Vertreibung, beschreibt (Hahn/Hahn 2001: 335-351). Während beide Arbeiten ihren historiographischen Fokus auf nationalstaatliche Fragen legen (vgl. François 205: 8-14), hat die dritte Publikation insofern einen transnationalen Schwerpunkt, als im Mittelpunkt ihres Interesses sowohl deutsche als auch polnische Erinnerungsorte stehen, deren Konzept auf das neue, von Klaus Zernack entwickelte Modell der ,Beziehungsgeschichte zurückzuführen ist (vgl. Górny/Hahn/Kończal u.a. 2012: 13-15).

In den Kapiteln 2-5 dieses Artikels wird gezeigt, wie sich die Debattenverläufe um drei Gedenkstättenprojekte darstellen; zum einen diejenigen um das in Berlin vom Bund der Vertriebenen (BdV) geplante Zentrum gegen Vertreibungen $(\mathrm{ZgV})$, zum anderen jene um das Europäische Zentrum gegen Vertreibungen, Zwangsumsiedlungen und Deportationen, das als Alternativprojekt zu dem ersteren konzipiert wurde. ${ }^{2}$ Außerdem sollen die Debatten und das gegenwärtig in Berlin entstehende Vertriebenenmuseum vorgestellt

1 Vgl. dazu Nora, Pierre (Hg.): Les lieux de memoire I. La Republique. Paris: Gallimard 1984; II. La Nation. Paris: Gallimard 1986; III. Les France. Paris: Gallimard 1992.

2 Vgl. dazu Troebst, Stefan (Hg.) (2006): Vertreibungsdiskurs und europäische Erinnerungskultur: Deutsch-polnische Initiativen zur Institutionalisierung. Eine Dokumentation. Osnabrück: Fibre. 
werden. Dies wird vorgenommen anhand der in den Medien geführten Debatten über die Errichtung eines $\mathrm{ZgV}^{3}$

Im Fokus der Dokumentation stehen die in der deutschen und polnischen Presse erschienenen Artikel, vor allem die in den zwei größten deutschen Zeitungen, Frankfurter Allgemeine Zeitung und Süddeutsche Zeitung und in den zwei größten polnischen, Gazeta Wyborcza und Rzeczpospolita, die auch die wichtigsten Standpunkte tschechischer Akteure zur Debatte mitberücksichtigen. Zur Erläuterung des historischen Hintergrunds werden auch einschlägige Sammel- und Konferenzbegleitbände sowie Dokumente herangezogen.

Kapitel 6 schließt mit der Überlegung an, inwieweit das Museumsprojekt die Funktion eines deutschen oder gar transnationalen Erinnerungsortes erfüllen kann, wobei sich der Aspekt von Transnationalität nur auf diese drei Länder begrenzt. Die Überlegungen können somit nur hypothetisch angestellt werden, weil, wie oben gesagt, dieses Museum erst in Begriff ist, zu entstehen.

\section{Die Debatte um die Errichtung des Zentrums gegen Vertreibungen}

Am 6. September 2000 gründete der BdV die Stiftung „Zentrum gegen Vertreibungen“, unter deren Schirmherrschaft das gleichnamige Zentrum errichten werden sollte. $\mathrm{Zu}$ Vorsitzenden dieser Stiftung wurden die BdV-Präsidentin und Bundestagsabgeordnete Erika Steinbach (CDU) und der SPD-Abgeordnete und Bundesgeschäftsführer Peter Glotz ernannt. In diesem Zentrum, als dessen Standort Berlin geplant wurde, sollten folgende Ziele umgesetzt werden:

Erstens: In einem Gesamtüberblick soll das Schicksal der mehr als 15 Millionen deutschen Deportations- und Vertreibungsopfer aus ganz Mittel-, Ost- und Südosteuropa mit ihrer Kultur und ihrer Siedlungsgeschichte [...] erfahrbar werden. [...]. In moderner musealer Form sollen die vielschichtigen Vorgänge [der Vertreibung] nachgezeichnet werden. In einer Requiem-Rotunde soll zudem Raum für Trauer, Anteilnahme und Verzeihen gegeben werden. [...] Drittens: gehören unverzichtbar zum Zentrum gegen Vertreibungen auch Vertreibung und Genozid an anderen Völkern, insbesondere in Europa. Allein in Europa waren bzw. sind mehr als 30 Volksgruppen von solchen Menschenrechtsverletzungen betroffen. Von den Albanern, Armeniern, Azeris über die Esten, Georgier, Inguschen, Krim-Tataren, Polen, Tschetschenen, Ukrainern bis zu den Weißrussen und griechischen Zyprioten und die singuläre Verfolgung und Massenvernichtung der Juden Europas durch den Nationalsozialismus. Über den Genozid 1914/15 am armenischen Volk durch das Osmanische Reich hat die Völkergemeinschaft indolent hinweggesehen. Ethnische „Flurbereinigung“ durch Zwangsumsiedlungen wurde 1922 vom Völkerbund nicht nur geduldet, sondern selbst beschlossen, und Hitler kalkulierte mit dem Desinteresse der Völkergemeinschaft bei seinen horriblen Vernichtungsplänen. Er setzte Schritt um Schritt sein grausames Werk an unse-

3 „Ein $\mathrm{ZgV“}$ sei hier verstanden als Sammelbegriff aller, der Erinnerung an Flucht und Vertreibung gewidmeter Gedenkstätten, weil sie sich in der Öffentlichkeit dieser drei Länder unter dieser Bezeichnung etabliert haben. Dies soll daraus resultiert haben, dass das Zentrum gegen Vertreibungen des BdV die erste Initiative war, die sehr kontrovers diskutiert wurde (vgl. dazu Łada 2006). 
ren jüdischen Mitbürgern und an den europäischen Juden fort. Er öffnete die Büchse der Pandora vollständig. Und so gab es auch nach ihm kein Halten. Neben der Vertreibung der Deutschen liefen die Vertreibung der Ostpolen durch Stalin und auch die der Ungarn durch Benes im Nachkriegszeitraum ab. Auf dem Balkan und in Tschetschenien sehen wir bis heute Bilder der Gewalt, getrieben von Rache und Vergeltung in einem Teufelskreis. Von anderen Kontinenten gar nicht zu sprechen. Gründe der Rechtfertigung dafür werden immer wieder gesucht. Es gibt sie nicht! Vertreibung und Genozid lassen sich niemals rechtfertigen. Sie sind immer ein Verbrechen, sie widersprechen den Menschenrechten und sie verharren im archaischen Denken von Blutrache. Das will die Stiftung nicht hinnehmen, sondern immer wieder mahnen und die Menschen bewegen, mitzufühlen und Anteil zu nehmen. (Grundsatzerklärung 2003)

Die Debatte um die Errichtung des ZgV hat indes mehr als ein Jahr zuvor in Deutschland begonnen, ausgelöst durch die Verkündung vom BdV und seinen Plänen zur Errichtung des $\mathrm{ZgV}$ in Berlin. Dies erfolgte am 29. Mai 1999 beim „Tag der deutschen Heimatvertriebenen“, der Festveranstaltung der Vertriebenenverbände, an dem man den fünfzigsten Jahrestag der Gründung der Bundesrepublik feierte. Der Termin schien bewusst gewählt zu sein, denn bei dieser Veranstaltung trat der damalige Bundesinnenminister Otto Schily auf, was ein entsprechend großes mediales Interesse hervorrief. In seiner Rede kritisierte er die Haltung der Linken gegenüber den Vertriebenen und sprach sich für ein „Zentrum gegen Vertreibungen“ in Berlin aus (vgl. Salzborn 2003a: 1122).

Anfänglich war das vom BdV geplante Zentrum nur eine innerdeutsche Angelegenheit. Charakteristisch war dabei, dass die prominentesten Parteien in Deutschland, also die CDU/CSU, die damals in der Opposition war, und die regierende Koalition von SPD und Bündnis90/Die Grünen, die Idee eines Zentrums gegen Vertreibungen unterstützten, was von der SPD wohl eher nicht zu erwarten war, weil sie sich seit der Ostpolitik Willi Brandts in den 1970er Jahren von den Vertriebenenorganisationen distanzierte (Kossert 2008: 181f.). In diesem Zusammenhang spricht der polnische Germanist, Publizist und Chefredakteur der katholischen Wochenzeitschrift Tygodnik Powszechny Wojciech Pięciak vom Ende der ideologischen Arbeitsverteilung, in der den Linken die Rolle zufiel, über die Verbrechen des nationalsozialistischen Regimes und über Deutsche als Täter zu sprechen, während die Rechten das Leid der Deutschen betonten und kommunistische Verbrechen brandmarkten (vgl. Pięciak 2002: 16-18). Im Laufe der Debatte, die sich um ein $\mathrm{ZgV}$ entfachte, zeigten sich aber große Unterschiede in den vorgeschlagenen Entwürfen zu dessen Gestaltung zwischen den Parteien. Die CDU hat grundsätzlich die Initiative des BdV unterstützt. Die rot-grüne Koalition wollte kein nationales, sondern ein europäisches Zentrum „im Dialog mit den Nachbarn“ gründen, was als Gegenentwurf zu der vom BdV geplanten nationalen Gedenkstätte zu sehen war (vgl. Debatte im Deutschen Bundestag über ein europäisches Zentrum gegen Vertreibungen am 16. Mai 2002, 2006: 38-56).

Diese Kontroverse sollte, wie es damals schien, im Bundestag ihr Ende finden. In der Mitte Mai 2002 dort geführten Debatte standen sich drei Ansätze gegenüber: das nationale $\mathrm{ZgV}$ des BdV, eine europäische Gedenkstätte als Vorschlag der Sozialdemokraten und Grünen, dessen Initiator der SPD-Abgeordnete Markus Meckel war, und ein europäisches Dokumentations- und Forschungszentrum der FPD. In der im Anschluss 
an dieser Debatte durchgeführten Abstimmung setzte sich das europäische Projekt der rot-grünen Koalition durch (vgl. Deutscher Bundestag, Drucksache 14/9068, 2002). In diesem Projekt wurde Wrocław als Standort des europäischen Zentrums vorgeschlagen. Den Vorschlag begründete Meckel wie folgt:

So kämen allein durch die Wahl des Ortes automatisch schon zwei Vertreibungsgeschichten nach Kriegsende 1945 zur Sprache - sowohl die der Deutschen aus den früheren deutschen Gebieten wie auch die mit der von Stalin durchgesetzten Westverschiebung Polens verbundene Vertreibung der Polen aus den ehemaligen polnischen Gebieten in der heutigen Ukraine, Weißrußland und Litauen. (Meckel 2006)

\section{Die Debatte über das ZgV in Polen}

Am 15. Mai 2002, am Vortag der Bundestagdebatte, wurde in der polnischen Tageszeitung Gazeta Wyborcza und in Die Welt ein Brief veröffentlicht, in dem die polnischen Publizisten Adam Krzemiński und Adam Michnik den deutschen Bundespräsidenten Johannes Rau und den polnischen Ministerpräsidenten Leszek Miller aufgerufen haben, ein europäisches Zentrum in Wrocław zu errichten (vgl. Michnik/Krzemiński 2002). Dieser Brief fand in Polen ein großes Echo und kann als Anstoß der polnischen öffentlichen Debatte über die Errichtung des $\mathrm{ZgV}$ angesehen werden. Der Standort Wrocław, über den in Polen viel diskutiert wurde, fand dort sowohl Anhänger als auch Gegner. Die Anhänger - darunter viele Intellektuelle aus dieser Stadt, Vertreter des Kulturlebens und der lokalen Verwaltungsbehörden - veröffentlichten im Juli 2003 einen Aufruf zur Errichtung eines derartigen Zentrums in Wrocław, in dem sie zum größten Teil die Argumente von Meckel, Michnik und Krzemiński wiederholten (vgl. Mecner 2003). ${ }^{4}$ Als Beispiel für häufig vorgebrachte Argumentation gegen Wrocław als den Standort eines Vertriebenenzentrums seien hier die Worte des damaligen Professors für Geschichte an der Universität Wrocław, Marek Czapliński angeführt:

[...] nie można moralnie zrównywać wypędzonych z Breslau z wysiedlonymi z Wileńszczyzny. Deportacje Niemców to jednak konsekwencja wojny zapoczątkowanej poparciem, jakiego udzielili Hitlerowi. Trzeba o nich pamiętać i rozmawiać, ale nie wolno zapominać, kto ponosi za to odpowiedzialność. To wbrew pozorom nie jest ta sama wspólnota doświadczeń.

[[...] man kann die Vertriebenen aus Breslau mit denen aus Wilna und seiner Umgebung moralisch nicht auf dieselbe Stufe stellen. Die Deportationen der Deutschen waren doch die Folge des Krieges, der seinen Anfang in der Unterstützung Hitlers nahm. Man muss an sie erinnern und von ihnen sprechen. Aber man darf nicht vergessen, wer dafür verantwortlich ist und entgegen dem Anschein ist das nicht dieselbe Erfahrungsgemeinschaft.] (Czapliński zit. nach Maciejewska 2002: 21)

4 Vgl. dazu den Aufruf der deutschen, tschechischen und polnischen Intellektuellen, die sich für ein europäisches $\mathrm{ZgV}$ mit Sitz in Breslau ausgesprochen haben; online unter: http://markus-meckel. de/wp-content/uploads/2009/12/Aufruf-Europ\%C3\%A4isches-Zentrum-gegen-Vertreibungen _mit-Unterzeichnern.pdf [Stand: 08.01.2018]. 
Wie der Aufruf der Intellektuellen aus Wrocław zeigt, war ein Teil der polnischen Elite einem europäischen Zentrum nicht abgeneigt. Bei den deutsch-polnischen Historikergesprächen konnten aber die letzteren das deutsche Paradigma, das sich mit dem Stichwort „das Jahrhundert der Vertreibung“ zusammenfassen lässt, nicht akzeptieren (vgl. Machcewicz 2006: 120). Laut diesem Konzept sollten die Zwangsmigrationen der Ausgangspunkt für die Betrachtung der europäischen Geschichte im 20. Jahrhundert sein. ${ }^{5}$

\section{Das Netzwerk Erinnerung und Solidarität}

Wie oben erwähnt, haben ostmitteleuropäische Historiker die Flucht und Vertreibung als Ausgangspunkt bei der Betrachtung der Geschichte des 20. Jahrhunderts und somit auch den Bau eines europäischen Zentrums abgelehnt. Geeinigt haben sie sich auf ein Netzwerk, in dem dieses Phänomen als Folge der beiden totalitären Regime im 20. Jahrhundert (Nationalsozialismus und Kommunismus) untersucht werden sollte. Der polnische Historiker Paweł Machcewicz begründete diese Entscheidung aus der polnischen Perspektive, die aber auch stellvertretend für die anderen Länder formuliert war:

So ein Netzwerk sollte sich nicht ausschließlich mit Zwangsumsiedlungen beschäftigen. Die Zwangsmigrationen bilden nur ein Fragment der Geschichte des 20. Jahrhunderts, sie sind alleine betrachtet gewissermaßen aus dem Zusammenhang herausgerissen. Sie sind nicht das Wichtigste und nicht das Drastischste, das wir erlebt haben. Das, was am wichtigsten und am universellsten in der Geschichte des 20. Jahrhunderts ist, was gemeinsam für Osteuropa und für Mitteleuropa ist, das sind die Erfahrung von zwei Totalitarismen: des Nazi-Totalitarismus und des Kommunismus. Symbole für das 20. Jahrhundert sind Auschwitz und der Gulag. Erst danach kommen die Zwangsumsiedlungen. [...] Ich denke, dass die Idee des Netzwerkes in Polen sehr gut aufgenommen wird, wenn es die Schlüsselereignisse des 20. Jahrhunderts berücksichtigt. Auf andere Weise werden die Polen es nicht verstehen können, warum man so viel Aufmerksamkeit, solche Anstrengungen, so viel Geld für das Erinnern an die Zwangsumsiedlungen aufwendet, wo man weiß, dass das deutsche Leid immer das größte sein wird - schon allein deshalb, weil die Deutschen von der Anzahl der Zwangsumgesiedelten immer die stärkste Gruppe bilden werden. (Machcewicz 2006: 120)

Zustande kommen konnte dieses Netzwerk Anfang Februar 2005 nach fast drei Jahren diplomatischen Tauziehens. Gegründet wurde es von Polen, der Slowakei, Ungarn, Deutschland und Österreich; Tschechien hat sich nur für einen Beobachterstatus entschieden (vgl. Absichtserklärung 2005). Seit seiner Gründung spielte das Netzwerk freilich keine bedeutende Rolle. Neben der offiziellen zwischenstaatlichen Debatte über die Errichtung eines europäischen Zentrums, dessen Ergebnis eben das europäische Netz-

5 Dieser Begriff ist eine Ableitung von Carl D. Wingenroth geprägten Begriffs „Das Jahrhundert der Flüchtlinge" (Wingenroth 1959). Er wurde auf Konferenzen zur Errichtung eines europäischen ZgV gebraucht. Vgl. dazu den Aufsatz des Historikers Philipp Ther (2006), erschienen im Sammelband zum internationalen Kolloquium, das unter dem Thema "Zwangsmigrationen in Europa 1938-1950" vom Institut für Europäische Geschichte Mainz vom 25. bis 28. September 2002 im Prager Clam-Gallas-Palais, dem Sitz des Archivs der Hauptstadt Prag, veranstaltet wurde. 
werk war, wurde nach wie vor die öffentliche Debatte, in deren Mittelpunkt das vom BdV forcierte Projekt stand, geführt, denn diese Organisation hat ihre Pläne nicht aufgegeben. In Polen war - gemessen am medialen Echo - die gesamte Öffentlichkeit, darunter auch die wissenschaftlichen und politischen Eliten, gegen dieses Projekt. Im Folgenden werden einige weitere wichtige Streitpunkte kurz besprochen. Der BdV wollte das $\mathrm{ZgV}$ unbedingt in Berlin in der Nähe des Holocaust-Mahnmals errichten (vgl. Wonka. 2000: 3). In Polen wurde die Stimme laut, dass durch die räumliche Nähe zum Holocaust auch die symbolische Nähe zu dessen jüdischen Opfern gesucht wird, um selbst einen ähnlichen Opferstatus zu erlangen (vgl. Pięciak 2002: 364). Als Gegenreaktion auf Berlin als Standort des Zentrums forderte kein geringerer als der Journalist, Historiker und Diplomat Władysław Bartoszewski, der auch in Deutschland großes Ansehen genoss, dazu auf, ein Zentrum der deutsch-polnischen Beziehungen von 1772 (erste Teilung Polens) bis 1945 zu errichten. Seinen Widerspruch gegen Berlin begründete er wie folgt:

Berlin ist für Polen in diesem Zusammenhang ein Symbol der Staatsmacht Preußens, für dessen Germanisierungs-Politik, dessen Unterdrückung der Slawen und dann der hitlerischen Staatsgewalt, für die polnischen und europäischen Juden ist Berlin der Ort jener Konferenz, auf der die Endlösung der Judenfrage Thema war. (Bartoszewski 2003: 9)

Auf Kritik stieß auch die geplante architektonische Form des $\mathrm{ZgV}$, denn es sollte in Form einer Requiem-Rotunde errichtet werden. Die symbolische Bedeutung des Requiems als Totenmesse wäre damit aufgerufen; die Rotunde als architektonischer Bautyp geht wiederum auf die Märtyrergräber zurück. Die Requiem-Rotunde würde damit im doppelten Sinne einen sakralen Rahmen schaffen und somit zur Entfaltung eines Opferpathos dienen (vgl. Shooman 2006: 166). Als sehr beunruhigend sah man in Polen auch die neue Betrachtung der Geschichte, nämlich prinzipiell eine aus der Opferperspektive. Der polnische Politikwissenschaftler Piotr Buras spricht in diesem Zusammenhang von einer Universalisierung der Geschichte. Dieser neuen Entwicklung liegt zugrunde, dass die Erfahrung der Opfer und nicht die der Täter der Ansatzpunkt bei der Betrachtung des Geschehenen ist, dessen Ursachen somit in den Hintergrund rücken (vgl. Buras 2003: 17f.). Wenn man annimmt, dass die vertriebenen Deutschen auch Opfer waren, dann passen sie wohl in dieses Schema hinein. Dem schon erwähnten polnischen Germanisten Wojciech Pięciak zufolge liegen dem günstigen Klima für die Selbstwahrnehmung der Deutschen als Opfer folgende Faktoren zugrunde: das Ende des Kalten Krieges, die Wiedervereinigung Deutschlands, die Bestätigung der Oder-Neiße-Grenze und zuletzt der Krieg im Kosovo (Pięciak 2003).

Der Kosovo-Krieg wurde tatsächlich zum Bestandteil der öffentlichen Debatte über die Errichtung des $\mathrm{ZgV}$ im Hinblick auf die Menschenrechte. Bei einem Festakt zum Tag der deutschen Heimatvertriebenen im Berliner Dom sagte der Innenminister Otto Schily (SPD) dazu: „Die Erinnerung an das millionenfache Leid der deutschen Vertriebenen [kann] dazu beitragen, künftig den Haß zwischen Völkern zu verhindern [...]. Wir haben gelernt, daß Minderheitenrechte akzeptiert werden können und müssen, ohne daß die Stabilität des Staates darunter leidet" (Schily 1999).

Pięciak hinterfragt die Kategorie der Menschenrechte als Ansatzpunkt bei der Betrachtung der Vertreibung der Deutschen kritisch: „Indem wir die Vertreibung der Deutschen 
ausschließlich nach der Kategorie der Menschenrechte beurteilen, lehnen wir den historischen Kontext ab“, schreibt Pięciak und fährt fort:

Traci na znaczeniu ciąg przyczynowo-skutkowy i pytanie, czy w realiach 1945 r., po traumie wojny i przesuwaniu granic, możliwe było życie milionów Niemców w powojennej Polsce i Czechosłowacji. W takiej perspektywie jak herezja brzmi konstatacja (w Polsce dla większości oczywista), że choć Polacy mogą ubolewać z powodu cierpień niewinnych, to nie nazwą wysiedleń „bezprawiem“, gdyż - choć okrutne - przyczyniły się one wtedy do pokoju i stabilności w Europie.

[Dabei verliert der kausale Zusammenhang von Ursachen und Folgen an Bedeutung und die Frage, ob in der Realität des Jahres 1945, nach dem Kriegstrauma und der Grenzverschiebung ein Zusammenleben der Deutschen und Polen, der Deutschen und Tschechien und Slowaken im Nachkriegspolen bzw. der Nachkriegstschechoslowakei möglich gewesen wäre. Aus dieser Perspektive erscheint die Konstatierung, die in Polen für die Mehrheit selbstverständlich ist, dass obwohl sie mit den Unschuldigen mitleiden können, sie die Aussiedlung nie als das „Unrecht“ bezeichnen würden, eine Art Ketzerei. Weil - wenn auch grausam - diese damals zum Frieden und zur Stabilität in Europa beigetragen hat.] (Pięciak 2003; übers. von T. D.)

Wie Pięciak weiter konstatiert, verlören die Tatsachen in ahistorischer Betrachtungsweise an Bedeutung.

Nicht akzeptiert wurde in Polen auch der in der Grundsatzerklärung der Stiftung „Zentrum gegen Vertreibungen“ vorgenommene Vergleich der Vertreibung der Deutschen mit dem Genozid an den Armeniern. Natürlich kann man hier sagen, dass der Völkermord an den Armeniern die erste kollektive Erfahrung von Vertreibung im 20. Jahrhundert war und deswegen haben die Initiatoren sie in ihr Projekt mit einbezogen. Wenn man aber berücksichtigt, dass ursprünglich ausgerechnet diesem historischen Ereignis eine selbständige Ausstellung gewidmet werden sollte (vgl. Boll/Kruke 2006: 16), kann man daraus schließen, dass sich dahinter der Gedanke verbarg, die Vertreibung der Deutschen mit dem Völkermord an diesem kaukasischen Volk gleichzusetzen. Dass den Initiatoren dieses Zentrums eben solch eine Intention zugrunde lag, könnte die Verbindung mit dem böhmischen Juden Franz Werfel, nach dessen Namen der Stiftungspreis benannt wurde, signalisieren (vgl. Brumlik 2005: 132). In seinem Roman Die vierzig Tage des Musa Dagh, der während der NS-Zeit in Deutschland verboten wurde, verarbeitete Werfel auf Basis ihm zugänglicher Forschungsmaterialien und journalistischer Prozessberichte den jungtürkischen Genozid an den Armeniern. Dabei stellte er „Deportationen als Bedingung und Vollzugsform des Genozides“ dar (Brumlik 2005: 132).

Sehr kritisch angenommen wurden in Polen auch solche Äußerungen wie die der Vorsitzenden des BdV, Erika Steinbach, die das Leid zu relativieren versuchten:

[...] wy cierpieliście w wyniku wywołanej przez nas wojny i okupacji, my w wyniku waszych bombardowań i wysiedleń; cierpiały dzieci Holokaustu tak samo jak dzieci wysiedlanych Niemców; 
[[...] ihr habt gelitten infolge des von uns ausgelösten Kriegs und der Besatzung, wir infolge eurer Bombenangriffe und der Vertreibung; es haben die Holocaust-Kinder gleich gelitten wie die Kinder der vertriebenen Deutschen.] (Steinbach zit. nach Kranz 2003)

In Polen wird grundsätzlich nicht infrage gestellt, dass auch deutschen Vertriebenen das Unrecht in menschlich-moralischem Sinne widerfuhr. Nicht anzunehmen war jedoch ein Versuch der Relativierung des kausalen Zusammenhangs von Ursachen und Folgen, durch die Menschen der beiden Nationen gelitten haben (vgl. Kranz 2003).

In dem Zentrum sah man auch die Gefahr der Relativierung der Geschichte, d. h. der Entkoppelung der Vertreibung der Deutschen von der ihr vorangegangenen nationalsozialistischen Volkstums- und Vernichtungspolitik in Polen, aber auch in den ost- und südosteuropäischen Ländern (vgl. Ruchniewicz 2002: 10).

Am heftigsten wurde in der polnischen Debatte jedoch Erika Steinbach selbst kritisiert. Außer ihrer kontroversen Äußerungen nahm man ihr dort aber auch in Tschechien übel, dass sie als Abgeordnete gegen den deutsch-polnischen Grenzvertrag und gegen die deutsch-tschechische Versöhnungserklärung stimmte. Darüber hinaus machte sie den EU-Beitritt beider Länder von der Regelung der Vermögensansprüche gegenüber deutschen Vertriebenen abhängig (vgl. Steinbach 1999: 11).

In der polnischen Öffentlichkeit diskreditierte sie sich zusätzlich, weil sie sich für eine „wahre“ Vertriebene hielt. So vertritt der polnische Publizist Jerzy Haszczyński den Standpunkt, dass Steinbach als Tochter eines Wehrmachtssoldaten ${ }^{6}$ aus der von Deutschen besetzten polnischen Stadt Rumia/Rahmel vertrieben wurde. Somit sei ihr auch der Opferstatus einer Vertriebenen so nicht anzuerkennen (Haszczyński 2003: 153-162).

Die öffentliche Debatte in Deutschland und Polen zeichnete sich dadurch aus, dass es, wie die polnische Politikwissenschaftlerin Agnieszka Łada feststellte, keinen Dialog zwischen den beiden Ländern in dieser Frage gegeben habe, was aber nicht bedeutete, dass man sowohl in Deutschland als auch in Polen die im jeweiligen Nachbarland in der Debatte geäußerten Meinungen und vertretenen Positionen nicht kommentierte (tada 2006: 6).

\section{Die Debatte in Tschechien}

Im Unterschied zu Polen wurde in Tschechien die Idee eines $\mathrm{ZgV}$ viel kritischer gesehen. Nur in engen intellektuellen Kreisen fand die Idee eines europäischen Zentrums seine Unterstützer. Zu ihnen gehörten Intellektuelle, die schon nach der samtenen Revolution begannen,

das bis dahin tradierte Schema der Nachkriegsvertreibungen als einer gerechten Vergeltung aller Verbrechen der kollektiv schuldigen Deutschen durch kritische Konzepte zu ersetzen [...]. (Pešek 2007: 196)

6 Steinbachs Vater stammte aus dem hessischen Hanau, ihre Mutter kam als Luftwaffenhelferin aus Berlin nach Rumia/Rahmel. 
Zu den Befürwortern eines europäischen Zentrums gehörten u.a. der Politikwissenschaftler Bohumil Doležal und der Historiker Emanuel Mandler (Kurski 2002: 14). Auch unter den Politikern hörte man einzelne Stimmen, die die Idee eines europäischen Zentrums befürworteten. Bemerkenswert ist hier die Äußerung des Senatspräsidenten der Tschechischen Republik Petr Pithart, der ein deutsches Zentrum zwar ablehnte, aber für eine europäische Lösung plädierte. Er begründete seine Meinung in einem Interview, das er der Süddeutschen Zeitung gab:

Für uns hat die Vertreibung mit dem Münchner Abkommen begonnen. Im Jahr 1938 sind zehntausende Tschechen aus dem an Deutschland gefallenen Grenzgebiet geflohen. Das haben sie als Vertreibung wahrgenommen. Die Besatzer hatten ihnen zu verstehen gegeben, dass sie dort nichts zu suchen haben. Für uns Tschechen ist daher die Darstellung unannehmbar, die Vertreibungen hätten erst mit der Vertreibung der Sudetendeutschen begonnen. Leider ist die Vertreibung der Sudetendeutschen auch nicht die letzte geblieben. Das hat sich in den neunziger Jahren in Südosteuropa gezeigt. Das ist ein europäisches Trauma. Keiner kann es monopolisieren. Es wäre nicht weitsichtig, wenn so ein Zentrum gerade deshalb in Berlin entstünde, weil einige Deutsche so tun, als ob vor der Vertreibung der Deutschen nichts Vergleichbares geschehen wäre. (Brössler 2003: 8)

Was daran noch mehr wundert, war Pitharts Vorschlag, dieses sogar in Tschechien zu errichten:

In unserem Grenzgebiet, wo es zu einer zweifachen Vertreibung kam, würden sich solche Orte finden. Natürlich würde dort dann auch das Problem der Vertreibung der Sudetendeutschen behandelt, aber das Zentrum dürfte sich nicht auf das deutsche Trauma beschränken. (Brössler 2003: 8)

Hochinteressant war auch seine Bemerkung über den Verlauf der Debatte um ein ZgV:

Ich wünsche mir mehr Beachtung für die Verriebenen [sic!] genauso wie für Leute aus dem Widerstand und den zur Zwangsarbeit Verschleppten. Die Zwangsarbeit ist ein globales, immer noch lebendiges Problem. Dagegen werden leider keine Zentren gebaut. Deutschland erlebt eine Debatte darüber, ob das Gedenken national oder europäisch sein soll. (Pithart zit. nach Brössler 2003: 8)

Pitharts letzte Worte geben zutreffend die neusten Entwicklungen in der deutschen Erinnerungskultur wieder, denn, wie Wojciech Pięciak (2003) feststellte, wäre solch eine Debatte noch in den neunziger Jahren unmöglich gewesen. Pithart wurde auch deswegen zitiert, weil er als Befürworter eines $\mathrm{ZgV}$ eher eine Ausnahme unter den tschechischen Politikern sowohl von den linken als auch von rechten Parteien war, was sich auf die in Tschechien bevorstehenden Parlamentswahlen zurückführen ließ, weil sowohl die regierenden Sozialdemokraten als auch die konservative ODS, deren Vorsitzender Václav Klaus war, mit der Verteidigung der sog. Beneš-Dekrete neue Wähler dazu gewinnen wollten (vgl. Majewski 200: 32-36). Die heißeste Phase der öffentlich-politischen tschechischen, aber auch polnischen Debatte fiel auf die Jahre 2002 und 2003, also 
auf die Zeit, in der diese Länder kurz vor dem EU-Beitritt standen und noch letzte Aufnahmebedingungen verhandelten. Im Unterschied zu Polen wurde in der tschechischen Öffentlichkeit die Idee des $\mathrm{ZgV}$ insgesamt deutlich weniger diskutiert. Im Mittelpunkt des öffentlichen Interesses standen die schon oben erwähnten so genannten Beneš-De$\mathrm{krete}^{7}$ (Buras 2003: 20). Wie brisant das Thema war, zeigt die 2002-2003 im Europäischen Parlament geführte Debatte. Denn von der rechtlichen Gültigkeit dieser Präsidialdekrete machte das Gremium seine Zustimmung über den Beitritt der Tschechischen Republik zur EU abhängig (Domnitz 2007: 25). Diese Debatte stieß in Tschechien auf große Resonanz und wurde im tschechischen Abgeordnetenhaus diskutiert. Die Abgeordneten „bedienten sich d[er] weit verbreitete[n] Argumentationsfigur [...], nach der die Präsidialdekrete eine Basis der tschechischen Rechtsordnung bildeten und deshalb nicht aufgehoben werden könnten“ (Domnitz 2007: 84). Das Ergebnis dieser Debatte war der am 24. April 2002 vom Tschechischen Abgeordnetenhaus verabschiedete Beschluss. Dieser besagt, dass die Rechts- und Eigentumsbeziehungen, die aus den Dekreten hervorgingen, „nicht in Frage zu stellen, unantastbar und unabänderlich“ seien und dass „die Restitutionsgesetzgebung Sache der tschechischen Verfassungsorgane sei“ (Domnitz 2007: 89). In Deutschland wurde das Vertreibungsthema im Zusammenhang mit den so genannten Beneš-Dekreten im Wahlkampf des CDU/CSU-Kandidaten Edmund Stoiber um den Posten des Bundeskanzlers vor der Bundestagswahl 2002 instrumentalisiert. Stoiber forderte, diese aufzuheben, was in der Tschechischen Republik eine heftige Reaktion auslöste (vgl. Kraft 350f.). Wie hitzig sie war, mag hier die Äußerung des damaligen tschechischen Premierministers, Miloš Zeman, veranschaulichen, der sagte, „dass für die Sudetendeutschen als ,fünfte Kolonne' Hitlers kein Platz in der Nachkriegstschechoslowakei gewesen sei“ (Zeman zit. nach Kraft 2005: 351).

Von der Aufhebung dieser Dekrete machte Stoiber die Aufnahme Tschechiens zur EU abhängig. Deren Aufhebung zöge Vermögensansprüche nach sich, die die Sudetendeutsche Landsmannschaft, unter deren starkem Einfluss der CDU/CSU-Kanzlerkandidat stand, geltend zu machen versuchte (vgl. Majewski 2003: 40f.).

Nach Stoibers Niederlage in den Bundestagswahlen 2002 und nach der offiziellen Bestätigung der rechtlichen Gültigkeit der Beneš-Dekrete seitens der EU auf dem Gipfeltreffen in Kopenhagen im Dezember desselben Jahres war das Vertreibungsthema aus dem Interesse der tschechischen Öffentlichkeit verschwunden (vgl. Majewski 2003: 40f.).

\section{Das sichtbare Zeichen gegen Flucht und Vertreibung}

Das Vertreibungsthema wurde im Herbst 2005 in Polen wiederaufgenommen. Der Grund dafür war die gemeinsame Erklärung der aus den Bundestagswahlen 2005

\footnotetext{
„Die tschechoslowakischen Präsidialdekrete. in der medialen Debatte als ,Beneš-Dekrete bezeichnet, regelten die Erlasse des Präsidenten Edvard Beneš vielfältige Aspekte des Wiederaufbaus des tschechoslowakischenn Staats nach 1945. [...] Die tschechoslowakische Nationalversammlung erklärte die Dekrete 1946 nachträglich zu geltendem Recht und damit zu gültigen Gesetzen." Domnitz (2007: 22) Zu den Wichtigsten aus der Perspektive dieses Artikels gehören: „die umfangreiche Aberkennung von Rechten und Eigentum von Angehörigen der deutschen und madjarischen Minderheiten im tschechoslowakischen Staatsgebiet".
} 
hervorgegangenen Großen Koalition CDU/SPD Gemeinsam für Deutschland. Mit Mut und Menschlichkeit. In dieser Erklärung hat sie sich „zur gesellschaftlichen wie historischen Aufarbeitung von Zwangsmigration, Flucht und Vertreibung“ bekannt. Dazu wollte sie

im Geiste der Versöhnung auch in Berlin ein sichtbares Zeichen setzen, um - in Verbindung mit dem Europäischen Netzwerk Erinnerung und Solidarität über die bisher beteiligten Länder Polen, Ungarn und Slowakei hinaus - an das Unrecht von Vertreibungen zu erinnern und Vertreibung für immer zu ächten. (Gemeinsam für Deutschland 2005)

Nach der mehr als drei Jahre dauernden Auseinandersetzung innerhalb der regierenden Schwarz-Rot-Koalition um die Form der geplanten Einrichtung wurde im Dezember 2008 zur Umsetzung dieses Koalitionsbeschlusses die Stiftung „Flucht, Vertreibung, Versöhnung" (SFVV) ins Leben gerufen (vgl. Dietrich 2008: 1). Der polnische Widerspruch, wenigstens auf der offiziellen Regierungsebene, richtete sich grundsätzlich nur gegen die Kandidatur Erika Steinbachs zum Sitz im Stiftungsrat der SFVV. Unter dem Druck der polnischen Seite, aber auch der deutschen Regierung, für die der Bau der Gedenkstätte von hoher Priorität war, hat Steinbach Anfang März 2009 ihre Kandidatur zurückgezogen. Seitdem ist die deutsch-polnische Auseinandersetzung auf der Regierungsebene vorerst beendet (vgl. Carstens 2009). Das „sichtbare Zeichen gegen Flucht und Vertreibung", das heute als Vertriebenenmuseum bezeichnet wird, kann als Kompromiss zu dem vom BdV geplanten $\mathrm{ZgV}$ angesehen werden. Sein Eckpunktepapier, das die Grundlage für die Erarbeitung eines Ausstellungskonzepts bildet, unterscheidet sich in vielerlei Hinsicht nicht von dem des BdV: „Die neue Einrichtung soll im Geist der Versöhnung und in der Kontinuität der Verständigungspolitik der Bundesrepublik Deutschland dem Ziel dienen, an das Unrecht der Vertreibung zu erinnern und Vertreibungen für immer zu ächten“" (Eckpunkte 2010: 4). Der Hauptunterschied zwischen ihnen besteht aber darin, dass die Vertreibung der Deutschen - im Gegensatz zu seinem Vorgängerprojekt - explizit im Kontext mit der NS-Vernichtungs- und Expansionspolitik betrachtet wird (vgl. Eckpunkte 2010: 1 u. 3). Beruhigend wirkte sich bestimmt auch die neue museale Form dieser Einrichtung aus, weil deren Planer von einem rein deutschen Martyrium, wie es der BdV noch vorsah, deutlich Abstand nahmen. Die Ausstellungskonzeption setzt deutlicher auf kognitive Wissensvermittlung, statt auf eine emotionale Anteilnahme bzw. Betroffenheit im Falle eines Denkmals.

Derzeit ist es freilich schwer einzuschätzen, welche endgültige Form dieses Projekt annehmen wird, auch wenn sein Gestaltungskonzept bereits im Juni 2010 in den vom ersten Direktor der SFVV Manfred Kittel vorgelegten Eckpunkten vorgestellt wurde. Wie kontrovers jedoch die Umsetzung dieses Projekts ist, zeigt der ständige Personalwechsel im Stiftungsrat und im wissenschaftlichen Beraterkreis der SFVV. Selbst Manfred Kittel musste im Dezember 2014 von seinem Posten zurücktreten. Nicht unumstritten waren auch Rücktritte vieler renommierter Historiker aus dem Beraterkreis, um hier nur die tschechische Historikerin Eva Kaiserová oder ihren polnischen Kollegen Tomasz Szarota zu nennen. Für den letzteren war die in den Gremien der SFVV forcierte Sichtweise der Vertreibung als „eines der schrecklichsten Ereignisse des Zweiten Weltkrieges“ nicht 
akzeptierbar. Er habe dagegen die „Vertreibung aus dem Leben“ für Millionen von Polen für etwas viel Schlimmeres gehalten (Stiftung 2009).

In seiner Botschaft unterscheidet sich das gegenwärtig in Berlin aufgebaute Vertriebenenmuseum von dem des BdV geplanten $\mathrm{ZgV}$ nicht: „[Es] will dazu beitragen, Vertreibung als gewalttätiges politisches Instrument und als Unrecht zu jeder Zeit und an jedem Ort zu ächten. Ihr Leitmotiv ist die Überzeugung von der Unteilbarkeit der Menschenrechte." (Eckpunkte 2010: 3) ${ }^{8}$ Die Zustimmung für solch eine Auslegung der Vertreibung ist weder in Tschechien noch in Polen in Sicht.

\section{Die Initiativen zum Gedenken der Flucht und Vertreibung als Erinnerungsort}

Wie bereits einleitend erwähnt, erleben Erinnerungsorte heutzutage eine hohe Konjunktur, und dies sowohl auf nationaler als auch transnationaler Ebene. Seit den 1990er Jahren gehören sie zu den meist verbreiteten Konzepten in den Geisteswissenschaften (vgl. Górny/Hahn/Kończal u.a. 2012: 9).

Im Folgenden wird überlegt, inwieweit die oben besprochenen Initiativen zum Gedenken der Flucht und Vertreibung die Funktionen eines deutschen und transnationalen Erinnerungsortes erfüllen können, wobei sich die Transnationalität auf Deutschland, Polen und Tschechien begrenzen wird.

Methodologisch wird dies unternommen anhand des Begriffs des Erinnerungsortes von Pierre Nora (1999) und dessen Nachfolgekonzepte von Etienne François und Hagen Schulze (2001) sowie des vom Zentrum für historische Forschung der Polnischen Akademie der Wissenschaften in Berlin erarbeiteten Ansatzes.

\subsection{Konzepte des Erinnerungsortes}

Die grundlegende Bestimmung des Begriffs Erinnerungsort stellte der französische Historiker Pierre Nora mit seinem dreiteiligen Werk Les lieux de memoire (1984) vor. Einen der wichtigsten Gründe für dessen Schaffung sieht er in dem sich allmählich vollendenden Prozess des Verlustes des nationalen Gedächtnisses, denn die Menschheit lebe heutzutage in einer Übergangsphase, in der „das Bewußtsein eines Bruchs mit der Vergangenheit einhergeht mit dem Gefühl des Abreißens des Gedächtnisses, zugleich aber [in] eine[m] Augenblick, da dies Abreißen noch soviel Gedächtnis freisetzt, daß sich die Frage nach dessen Verkörperung stellen läßt“" (Nora 1990: 304). Schuld am Gedächtnisverlust ist nach Nora u.a. der zivilisatorische Fortschritt, der die Gedächtnisse ganzer sozialer Gruppen, wie z.B. der Bauern, löscht. Er behauptet, dass es deshalb lieux de memoire gibt, weil es keine milieu memoire existieren (vgl. Nora 1990: 304). Er bezeichnet Erinnerungsorte als „Überreste“, die die Funktion der Erhaltung des historischen Bewusstseins haben (vgl. Nora 1990: 16). Unter solchen Überresten versteht er das, „was eine Gemeinschaft [...] künstlich und willentlich ausscheidet, aufrichtet, etabliert, kons-

8 Vgl. dazu das neueste Konzept für die Dauerausstellung der SFVV vom Juni 2017, online unter: http:// www.sfvv.de/de/presse/stiftung-ver\%C3\%B6ffentlicht-konzept-f\%C3\%BCr-die-dauerausstellung [Stand: 08.01.2018]. 
truiert, dekretiert, unterhält“ (Nora 1990: 310). Die Erinnerungsorte zeichnen sich nach Nora durch eine gewisse Ambivalenz aus, die für eine moderne Gesellschaft eher typisch ist:

Sie sind die Bräuche einer Gesellschaft ohne Brauchtum; flüchtige Heiligtümer in einer Gesellschaft der Entheiligung; besondere Bindungen in einer Gesellschaft, die alle Besonderheiten schleift; faktische Differenzierungen in einer Gesellschaft, die aus Prinzip nivelliert, Erkennungszeichen und Merkmale der Gruppenzugehörigkeit in einer Gesellschaft, die dazu tendiert, nur noch gleiche und identische Individuen anzuerkennen. (Nora 1990: 310)

Der weitere Grund für die Entstehung eines Erinnerungsortes resultiert nach Nora aus der landläufigen Überzeugung, dass heute kein spontanes Gedächtnis existiert. Deshalb wird es es in einer organisierten, institutionalisierten Form etabliert, durch Erinnerungsorte wie Archive, Jahrestage, Feiern oder gar Nachrufe. Dieser Überzeugung liegt die Befürchtung zugrunde, dass die Geschichte ohne die Erinnerungsorte in Vergessenheit geraten würde (vgl. Nora 1990: 309f.).

Nach Noras Verständnis kann ein Erinnerungsort ein topographischer Ort sein, wie z.B. ein einfaches Kriegerdenkmal in einem Dorf oder die Statue des Paris, ein Gebäudekomplex wie das Schloss von Versailles oder das Pariser Notre-Dame. Er kann aber auch mit realen und mythischen Personen verbunden sein wie Napoleon oder Jeanne d'Arc. Zu Erinnerungsorten zählt er auch Embleme wie die Trikolore, Ereignisse wie die Schlacht um Verdun, Feiertage wie der 14. Juli, Rituale wie die Salbung der Könige in Reims oder Museen, z.B. der Louvre (vgl. Nora 1990: 7). Dabei lassen sich die Erinnerungsorte in materielle und immaterielle sortieren. $\mathrm{Zu}$ den materiellen gehören u.a. Gebäude, Denkmäler und Museen, zu den immateriellen Ereignisse, Feiertage oder Rituale. Die Erinnerungsorte können einen materiellen, symbolischen oder funktionalen Sinngehalt enthalten. Diese drei Merkmale gehen notwendig ineinander über, denn ein Erinnerungsort benötigt wenigstens zwei davon, um als solcher zu gelten. So wird ein Archivdepot, dessen ursprüngliche Bedeutung in seiner Materialität besteht, erst durch seine Symbolik zum Erinnerungsort. Ähnlich verhält es sich z.B. mit einem Kriegsveteranenverein, der primär als rein funktional gilt. Sie verwandelt sich in einen Erinnerungsort erst dann, wenn in ihm Rituale kultiviert werden. Alle drei Merkmale sind in dem abstrakten Erinnerungsort „Generation“ enthalten. Er sei also

materiell aufgrund seines demographischen Inhalts, funktional qua Hypothese, denn er bewirke gleichzeitig die Kristallisierung der Erinnerung und ihre Weitergabe, per Definition aber ist er symbolisch, denn er charakterisiert anhand eines Ereignisses oder einer Erfahrung, die nur wenige erlebt hätten, eine Mehrheit, die an ihnen nicht teilgehabt hatte. Was sie konstituiert, ist ein Wechselspiel von Gedächtnis und Geschichte, eine Interaktion zwischen beiden Faktoren, die zu ihrer wechselseitigen Überdetermination führt. (Nora 1990: 26)

Wie bereits gesagt, erfreut sich das von Nora in den 1980er und Anfang der 1990er Jahre ausgearbeitete Konzept des Erinnerungsortes einer großen Popularität, vor allem 
in den Geisteswissenschaften in Deutschland. Die deutschen Historiker Etienne François und Hagen Schulze verweisen auf die Wirkung der in ihm langfristig enthaltenen Erinnerung, die sich über mehrere Generationen erstreckt. Das Erinnerungsort ist als „Kristallisationspunkt kollektiver Erinnerung und Identität" gar mit Symbolen und Emotionen überladen, „in gesellschaftliche, kulturelle und politische Üblichkeiten eingebunden“ und in dem Maße veränderlich, als „sich die Weise seiner Wahrnehmung, Aneignung, Anwendung und Übertragung verändert“ (Francois/Schulze 2001: 17f.). Die Autoren der neunbändigen Serie Deutsch-Polnische Erinnerungsorte haben das Konzept der gemeinsamen, geteilten und parallelen Erinerungsorte entwickelt. Vom Interesse sind hier vor allem die zwei ersteren.

Gemeinsame Erinnerungsorte - so die Herausgeber dieser Serie Hans Henning Hahn und Robert Traba - suggerieren, dass ihre Funktionen weitgehend gleich oder ähnlich seien. Geteilte Erinnerungsorte beziehen sich nach ihnen zwar auf dasselbe Erinnerungsobjekt, unterschieden sich aber in seiner Funktionalisierung für den Identitätshaushalt und damit in ihrer Rolle in der Erinnerungskultur. Hierbei decken sie sich wohl höchstens partiell, oft überhaupt nicht (vgl. Hahn/Traba 2015: 22).

\subsection{Das Vertriebenenmuseum als deutscher und transnationaler Erinnerungsort}

Die Erinnerung an Flucht und Vertreibung war eigentlich die ganze Zeit im bundesrepublikanischen bzw. deutschen kollektiven Gedächtnis präsent. Dennoch unterlag ihre Intensität unterschiedlichen konjunkturellen politischen und sozialen Schwankungen. In den 1950er und 1960er Jahren war diese Erfahrung ein wichtiger Bestandteil nationaler Identitätsstiftung (vgl. Scholz/Röger/Niven 2015: 9), weil gewisse politische Kräfte die Bundesrepublik viktimisierten und daher auch die traumatischen Erfahrungen der Vertriebenen sehr stark artikuliert wurden (vgl. Markovits/Reich 1998: 37). Anders war das etwa in der Zeit der Brandt'schen Ostpolitik, in der die Vertriebenen aus dem Fokus des öffentlichen Interesses verschwunden waren (vgl. Franzen 2003: 52).

Das Ende des Kalten Krieges und die Wiedervereinigung Deutschlands, infolge deren die deutsch-polnische Grenze an der Oder und Neiße von Deutschland anerkannt wurde, schufen ein gelegenes Klima für die Erinnerung an Flucht und Vertreibung (vgl. Scholz/Röger/Niven 2015: 9), was Initiativen zum Bau eines ZgV in Deutschland begünstigte. Eines der wichtigsten Argumente, die der BdV als Initiator seines Projekts nannte, war das Fehlen der Vertriebendenkmäler in Deutschland, was aber der deutsche Historiker Stephan Scholz in seiner Dissertation widerlegte. Er wies darin nach, dass die Erinnerung an eigene Vertreibung in der deutschen Topographie sehr ausdrücklich konserviert wurde, wovon allein die Zahl von 1584 Denkmälern zeugt (vgl. Scholz 2015: 10, 41). Das in Berlin gebaute Vertriebenenmuseum soll aber kein klassisches Denkmal sein, sondern eine Dokumentationsstelle und eine Gedenkstätte (vgl. Eckpunkte 2010: 6, 13). Denkmäler, Gedenkstätten und Museen unterscheiden sich in ihrer Funktion. Während Denkmäler die ästhetischste und emotionalste Erinnerungsform sind, setzen Gedenkstätten einen reflexiven Umgang mit dem Erinnerungsort voraus; die Museen dagegen dienen der Aufarbeitung und Interpretation der Vergangenheit (vgl. Borsdorf/ Grütter, 1999: 6). Es steht auch außer Frage, dass in Deutschland auch schon viele der 
Flucht und Vertreibung gewidmete Ausstellungen gezeigt wurden (es seien beispielsweise erwähnt: „Flucht, Vertreibung, Integration“ im Haus der Geschichte in Bonn, 2005; „Die erzwungenen Wege“, in Kronprinzenpalais in Berlin, 2006), es gibt aber bis jetzt keinen zentralen Ort, der diese für Deutschland offensichtlich sehr wichtige historische Ereignisse präsentiert hätte.

Stephan Scholz sieht das Motiv für das Bemühen um die Errichtung eines deutschen $\mathrm{ZgV}$ vielmehr in der unter dem Einfluss des BdV in den politischen Kreisen (auch der großen Koalition, die 2005 den Bau des sichtbaren Zeichens beschloss) etablierten Überzeugung, dass das Thema Flucht und Vertreibung aus dem deutschen kollektiven Gedächtnis verdrängt wurde oder wird (vgl. Scholz 2015: 10). Dass diese Überzeugung gängig ist, zeigt u.a. die Rede des Bundespräsidenten Joachim Gauck, die er am 3. September 2016 anlässlich des Tags der Heimat hielt. Darin plädierte er dafür, das „Schicksal dieser Menschen aus dem Erinnerungsschatten“ (Gauck 2016) zu holen. Der Verfasser dieses Beitrags ist vielmehr der Ansicht, dass ihr Schicksal nicht tabuisiert wurde, sondern, wie bereits oben geschrieben, dass es konjunkturellen Schwankungen unterlag. Die Überzeugung über die Vertreibung als ein Tabuthema bereitete nach Scholz den Boden zur öffentlichen Erinnerung an die deutschen Vertreibungsopfer und für die Förderung solcher Initiativen wie das ZgV vor (vgl. Scholz 2015: 11). Diese Initiative wurde zusätzlich von dem seit der Jahrtausendwende in Deutschland geführten Opferdiskurs begünstigt, der sich auf die Schicksale der Zivilbevölkerung bezogen hat. Neben der Vertreibung wurden in ihm noch zwei weitere Erfahrungskomplexe thematisiert: die Alliierten-Bombenangriffe auf deutsche Städte und die Massenvergewaltigungen der deutschen Frauen (vgl. Assmann 2006: 184). Andererseits kann aber der Grund zum Bau eines deutschen Vertriebenenzentrums tatsächlich in der sich auflösenden Erinnerung an Flucht und Vertreibung gesehen werden. Diese Auflösung geht mit dem Absterben der Betroffenen einher, die die Träger des Erfahrungsgedächtnisses sind (vgl. Assmann 2006: 192f.). Damit die Erlebnisse mit dem Auflösen des Erfahrungsgedächtnisses nicht verschwinden, müssen sie weitergegeben werden. Der Prozess, durch den die Weitergabe meist erfolgt, bezeichnen Gedächtnisforscher als Transformation des kommunikativen Gedächtnisses ins kulturelle Gedächtnis. Christoph Cornelißen definiert ihn wie folgt:

[Das kommunikative Gedächtnis] bezieht sich auf die Erinnerung an tatsächliche beziehungsweise mündlich tradierte Erfahrungen, die einzelne oder Gruppen von Menschen gemacht haben. Im Fall des kommunikativen Gedächtnisses ist die Rede von einem gesellschaftlichen „Kurzzeitgedächtnis“, dem in der Regel maximal drei aufeinander folgende Generationen zuzurechnen sind, die zusammen eine „Erfahrungs-, Erinnerungs- und Erzählgemeinschaft“ bilden können. Während diese im unaufhörlichen Rhythmus der Generationenabfolgen meist leise und unmerklich vergeht, wird das ,kulturelle Gedächtnis als ein epochenübergreifendes Konstrukt begriffen. Im Allgemeinen werden damit der in jeder Gesellschaft und jeder Epoche eigentümliche Bestand an Wiedergebrauchs-Texten, -Bildern und -Riten bezeichnet, „in deren Pflege sie ihr Selbstbild stabilisiert und vermittelt“. Es ist „ein kollektiv geteiltes Wissen vorzugsweise (aber nicht ausschließlich) über die Vergangenheit, auf das eine Gruppe ihr Bewusstsein von Eigenheit und Eigenart stützt“. (Cornelißen 2003: 554, Zitate aus Jan Assmanns Aufsatz Kollektives Gedächtnis und kulturelle Identität) 
Was für das Vertriebenenmuseum als deutscher Erinnerungsort sprechen kann, ist das Argument, dass die Flucht und Vertreibung eine für dieses Land sehr wichtige Erfahrung ist.

Das Opfernarrativ, falls es sich bei der Darstellung der Flucht und Vertreibung in ihm durchsetzt, könnte auch eine Brückenfunktion zwischen den West- und Ostdeutschen Erinnerungen, deren meistens viele und fortgesetzte Trennungsgeschichten zugrunde liegen, erfüllen. Es könnte hier zu einem neuen Mythos werden, der die Erinnerungskulturen der beiden Staatteile verbinden könnte (vgl. Assmann 2006: 192).

Wie das Museum die Erinnerung an Flucht und Vertreibung gestalten wird, hängt auch davon ab, inwieweit es ihm gelingen würde, eines seiner wichtigsten Ziele umzusetzen, nämlich diese Erinnerung in das deutsche kollektive Gedächtnis als das zentrale historische Ereignis zu verorten (vgl. Eckpunkte 2010: 4).

\subsection{Das Vertriebenenmuseum als ein transnationaler Erinnerungsort}

Das Vertriebenenmuseum in Berlin wird auch einen europäischen Charakter haben: Bereits auf der Gegenstand-Ebene soll die europäische Dimension der Vertreibung beachtet werden.

Wie aber die Debatte um die Errichtung des ZgV gezeigt hat, ist es wenig wahrscheinlich, dass dieses Museum als ein gemeinsamer Erinnerungsort gemäß der Definition von Hahn und Traba gesehen werden kann. Dies ergibt sich daraus, dass die Erinnerung an Flucht und Vertreibung in der deutschen, polnischen und tschechischen Erinnerungskultur voneinander divergieren. Im Fall Deutschlands und Polens können sie als ein geteilter Erinnerungsort auftreten, weil Polen auch im Laufe und gegen Ende des Zweiten Weltkriegs aus ihren Ostgebieten vertrieben wurden. Im Unterschied zu Deutschland hat die Erinnerung an die Vertreibung der Polen in diesem Land ausschließlich einen lokalen Charakter und war nie Bestandteil eines von oben organisierten nationalen Gedächtnisses. Sie hat sich jedoch im Familiengedächtnis fest verankert (vgl. Chwin 2003).

Noch weniger wahrscheinlich ist, dass das Vertriebenenmuseum sich als ein gemeinsamer oder gar geteilter deutsch-tschechischer Erinnerungsort etablieren wird, und dies vor allem aufgrund der in diesem Artikel schon besprochenen Kontroverse um die sog. Beneš-Dekrete.

Es ist auch kaum zu erwarten, dass das Vertriebenenmuseum in Berlin zu einem transnationalen Erinnerungsort sein wird, für den Moritz Csáky die Abkehr von der „nationale[n] Besetzung des kollektiven Gedächtnisses“ sowie „Mehrfunktionalität konkreter und symbolischer Erinnerungsorte“ (Hahn/Traba 2015: 18) voraussetzt. Um dies umsetzen zu können, müsste man aber über nationale Denk- und Deutungsmuster hinausgehen, was allerdings heutzutage kaum möglich zu sein scheint, und dies erst recht, wenn die politische Lage in Ostmitteleuropa eher eine erneute Zuwendung zum Konzept des Nationalstaates signalisiert.

Mehr Hoffnung könnte man in das „Europäische Netzwerk Erinnerung und Solidarität“ setzen, das in Verbindung mit diesem Museum zu einem Erinnerungsort, wenn auch einem dezentralen, sein würde. Diese Idee war auch in dem Koalitionsvertrag von CDU und SPD aus dem Jahr 2005 enthalten (vgl. Gemeinsam für Deutschland 2005). Dieses 
Netzwerk müsste aber zuerst revitalisiert werden, wofür zunächst wieder der politische Wille der an ihm beteiligten Staaten notwendig ist.

\section{Schluss}

Die in diesem Aufsatz besprochene Debatte hat veranschaulicht, dass Flucht und Vertreibung immer noch ein heikle Themen sind und dass es derzeit unmöglich scheint, an dieses Phänomen als gemeinsame nationenübergreifende Erfahrung zu erinnern, was die misslungene Umsetzung von Projekten, beispielsweise eines europäischen Zentrums gezeigt hat. Darin machte sich auch eine Verschiebung in Selbstwahrnehmungsprozessen deutlich: Die Frage nach der deutschen Verantwortung wurde verstärkt auch in ihrer Opferrolle diskutiert. Erinnerung auch an deutsche Opfer wird heutzutage als etwas normales und selbstverständliches angesehen.

Zurzeit ist es nicht sicher, inwieweit das in Berlin gebaute Vertriebenenmuseum die Funktion eines gesamtdeutschen Erinnerungsortes erfüllen kann. Es hat zwar die Merkmale des Erinnerungsortes laut dessen Begriffe von Pierre Nora und Etienne François, aber ob er zum gesamtdeutschen Erinnerungsort sein wird, wird letztendlich davon abhängen, wie sich in ihm die Erinnerung an Flucht und Vertreibung entwickeln wird. Als transnationaler Erinnerungsort wird erwohl in absehbarer Zeit nicht akzeptiert werden.

\section{LITERATUR}

a) Monographien, Sammelbände:

Assmann, Aleida (2006): Der lange Schatten der Vergangenheit. Erinnerungskultur und Geschichtspolitik. München: Beck.

Borsdorf, Ulrich / Grütter, Heinrich Theodor (Hgg.) (1999): Orte der Erinnerung: Denkmal, Gedenkstätte, Museum. Frankfurt/Main/New York: Campus Verlag.

Brumlik, Micha (2005): Wer Sturm sät: Die Vertreibung der Deutschen. Berlin: Aufbau-Verlag GmbH.

Buras, Piotr (2003): Powrót wypędzonych, czyli (nie tylko) niemieckiego sporu o pamięć ciąg dalszy [Die Rückkehr der Vertriebenen, also (nicht nur) die Fortsetzung des deutschen Streites um die Erinnerung]. In: Buras, Piotr / Majewski, Piotr (Hgg.): Pamięć wypędzonych. Grass, Beneš i środkowo-europejskie rozrachunki. Antologia tekstów polskich, niemieckich i czeskich [Die Erinnerung der Vertriebenen. Grass, Beneš und mitteleuropäische Abrechnungen. Eine Anthologie polnischer, deutscher und tschechischer Texte]. Warszawa: Biblioteka „WIĘZI“, 5-20.

Debatte im Deutschen Bundestag über ein europäisches Zentrum gegen Vertreibungen am 16. Mai 2002 (2006). In: Troebst, Stefan (Hg.): Vertreibungsdiskurs und europäische Erinnerungskultur: Deutsch-polnische Initiativen zur Institutionalisierung. Eine Dokumentation. Osnabrück: Fibre.

Domnitz Christian (2007): Die Beneš-Dekrete in parlamentarischer Debatte Kontroversen im Europäischen Parlament und im tschechischen Abgeordnetenhaus vor dem EU-Beitritt der Tschechischen Republik. Münster: LIT Verlag.

François, Etienne (2005): Pierre Nora und die « lieux de memoire ». In: Nora, Pierre (Hg.): Erinnerungsorte Frankreichs. München: C. H. Beck, 7-14.

François, Etienne / Hagen, Schulze (2001): Einleitung. In: Deutsche Erinnerungsorte I. München: C. H. Beck, 9-26. 
Górny, Maciej / Hahn, Hans Henning / Kończal, Kornelia (Hgg.) (2012): Zur Einführung. In: Deutsch-Polnische Erinnerungsorte Band 3: Parallelen. Paderborn: Ferdinand Schöningh, 11-20.

Hahn, Eva / Hahn, Hans Henning (2001): Flucht und Vertreibung. In: François, Etienne / Schulze, Hagen (Hgg.): Deutsche Erinnerungsorte. Bd. I. München: Verlag C. H. Beck, 335-351.

Hahn, Hans Henning / Traba, Robert (2015): Wovon die deutsch-polnischen Erinnerungsorte (nicht) erzählen. In: Hahn, Hans Henning / Traba, Robert (Hgg.): Deutsch-Polnische Erinnerungsorte. Bd I. Paderborn: Ferdinand Schöningh, 9-50.

Haszczyński, Jerzy (2003): Nie tylko pani Steinbach. Reportaże i szkice [Es geht nicht nur um Frau Stenbach. Reportagen und Skizzen]. Warszawa: Wydawnictwo El-Ka.

Kossert, Andreas (2008): Kalte Heimat: Die Geschichte der deutschen Vertriebenen nach 1945. München: Siedler Verlag.

Kraft., Claudia (2005): Der Platz der Vertreibung der Deutschen im historischen Gedächtnis Polens und der Tschechoslowakei/Tschechiens. In: Cornelißen, Christoph / Holec, Roman / Pešek, Jiří (Hgg.): Diktatur - Krieg - Erinnerungskulturen in Tschechien, der Slowakei und Deutschland seit 1945. Veröffentlichungen zur Kultur und Geschichte im östlichen Europa, Bd. 26. Essen: Klartext, 329-354.

Kruke, Anja / Boll, Friedhelm (2006): Einleitung In: Kruke, Anja (Hg.): Zwangsmigration und Vertreibung: Europa im 20. Jahrhundert. Berlin: Dietz, 9-29.

Łada, Agnieszka (2006): Debata publiczna na temat powstania Centrum przeciw Wypędzeniom w prasie polskiej i niemieckiej [Öffentliche Debatte über die Entstehung des Zentrums gegen Vertreibungen anhand der Polnischen und deutschen Presse]. Wrocław: Oficyna Wydawnicza ATUT.

Machcewicz, Paweł (2006): Stellungnahme des Leiters des Büros für öffentliche Bildung des polnischen Instituts für Nationales Gedenken sowie Berater von Sejm und Kulturministerium: „Das Netzwerk aus polnischer Sicht“. In: Troebst, Stefan (Hg.): Vertreibungsdiskurs und europäische Erinnerungskultur: Deutsch-polnische Initiativen zur Institutionalisierung. Eine Dokumentation. Osnabrück: Fibre, 117-120.

Majewski, Piotr (2003): Czeski rozrachunek - dekrety Beneša i stosunki czesko-niemieckie po 1989 roku [Tschechische Aufrechnung - die Beneš-Dekrete und die tschechisch-deutschen Beziehungen nach dem Jahr 1989]. In: Buras, Piotr / Majewski, Piotr (Hgg.): Pamięć wypędzonych. Grass, Beneš i środkowo-europejskie rozrachunki. Antologia tekstów polskich, niemieckich i czeskich [Die Erinnerung der Vertriebenen. Grass, Beneš und mitteleuropäische Abrechnungen. Eine Anthologie polnischer, deutscher und tschechischer Texte]. Warszawa: Biblioteka „WIĘZI“, 21-48.

Markovits, Andrei S. / Reich, Simon (1998): Das deutsche Dilemma: die Berliner Republik zwischen Macht und Machtverzicht. Berlin: Alexander Fest Verlag.

Meckel, Markus (2006): Warum Breslau? Die Leiden der Vertriebenen sollten Thema von Erinnerung und Nachdenken sein. In: Troebst, Stefan (Hg.): Vertreibungsdiskurs und europäische Erinnerungskultur: Deutsch-polnische Initiativen zur Institutionalisierung. Eine Dokumentation. Osnabrück: Fibre, 31-33.

Nora, Pierre (1990): Zwischen Geschichte und Gedächtnis. Berlin: Wagenbach.

Pešek, Jiří (2007): Zwangsmigrationen von Tschechen und Deutschen 1938-1949 in der tschechischen Geschichtswissenschaft seit 1989. In: Melville, Ralph / Pešek, Jiří / Scharf, Claus (Hgg.): Zwangsmigrationen im mittleren und östlichen Europa: Völkerrecht - Konzeptionen - Praxis (1938-1950). Mainz: Vandenhoeck \& Ruprecht, 193-202.

Pięciak, Wojciech (2002): Niemiecka pamięć. Wspótczesne spory w Niemczech o miejsce III Rzeszy w historii, polityce i tożsamości (1989-2001) [Deutsche Erinnerung. Gegenwärtige Streite in Deutschland über den Ort des Dritten Reiches in der Geschichte, Politik und Identität (1989-2001)]. Kraków: Wydawnictwo Uniwersytetu Jagiellońskiego.

Scholz, Stephan (2015): Vertriebenendenkmäler. Topographie einer deutschen Erinnerungslandschaft. Paderborn: Ferdinand Schöningh.

Scholz, Stephan / Röger, Maren / Niven, Bill (Hgg.) (2015): Die Erinnerung an Flucht und Vertreibung. Ein Handbuch der Medien und Praktiken: Einleitung. Paderborn: Ferdinand Schöningh, 9-14.

Shooman, Yasemin (2006): Konfliktlinien in der Debatte um ein Zentrum gegen Vertreibungen in Deutschland [Linie podziału w debacie wokół Centrum przeciw Wypędzeniom w Niemczech]. In: Pappai, Anna-Sophia / Pec, Michał Oskar / Zalewski, Krzysztof Marcin (Hgg.): Wypędzenia i co dalej? Materiały z seminarium polsko-niemieckiego dla studentów - Vertreibungen und was weiter? Beiträge eines deutsch-polnischen Seminars für Studierende. Warszawa: Instytut Historyczny Uniwersytetu Warszawskiego u. Wydawnictwo DiG, 163-177. 
Ther, Philipp (2006): Ein Jahrhundert der Vertreibung. Die Ursachen von ethnischen Säuberungen im 20. Jahrhundert. In: Kruke, Anja (Hg.): Zwangsmigration und Vertreibung: Europa im 20. Jahrhundert. Berlin: Dietz, 19-38.

\section{b) Zeitschriften:}

Cornelißen, Christoph (2003): Was heißt Erinnerungskultur? Begriff - Methoden - Perspektiven. In: Geschichte in Wissenschaft und Unterricht 54, Velber bei Hannover, 548-563.

Franzen, K. Erik (2003): In der neuen Mitte der Erinnerung. Anmerkungen zur Funktion eines Opferdiskurses. In: Zeitschrift für Geschichtswissenschaft 51, Nr. 1, Berlin, 49-53.

Ruchniewicz, Krzysztof (2002): Das Problem der Zwangsaussiedlung der Deutschen aus polnischer und deutscher Sicht in Vergangenheit und Gegenwart. Berichte und Forschungen. In: Jahrbuch des Bundesinstituts für Kultur und Geschichte der Deutschen im östlichen Europa, Bd. 10, München, 8-28.

Salzborn, Samuel (2003): Geschichtspolitik in den Medien: Die Kontroverse über ein „Zentrum gegen Vertreibungen“. In: Zeitschrift für Geschichtswissenschaft 51, Nr. 12, Berlin, 1120-1131.

Wingenroth, Carl (1959): Das Jahrhundert der Flüchtlinge. In: Außenpolitik 10, 491-499.

\section{c) Zeitungen:}

Bartoszewski, Władysław (2003): Wider das selektive Erinnern. In: Frankfurter Allgemeine Zeitung, 06.08.2003, 9.

Brössel, Daniel (2003): Zentrum gegen Vertreibung in Tschechien denkbar. Interview mit Petr Pithart. In: Süddeutsche Zeitung, 18.07.2003, Nr. 163, 8.

Carstens, Peter (2009): Erika Steinbach: Anerkennung durch Verzicht. In: Frankfurter Allgemeine Zeitung, 04.03.2009; online unter: http://www.faz.net/artikel/C30923/erika-steinbach-anerkennung-durch -verzicht-30047750.html [Stand: 30.03.2017].

Deutscher Bundestag, Drucksache 14/9068, Berlin, den 15. Mai 2002; online unter: http://dip.bundestag.de /btd/14/090/1409068.pdf [Stand: 14.03.2017].

Dietrich, Stefan (2008): Erkenntnisgewinn auf Umwegen. In: Frankfurter Allgemeine Zeitung, 4.12.2008, Nr. 284, 1.

Kranz, Jerzy (2003): Dlaczego trudno się porozumieć? [Warum ist es schwer, sich zu verständigen?]. In: Rzeczpospolita, 20.12.2003, Nr. 51; online unter: http://new-arch.rp.pl/artykul/465803.html [Stand: 17.03.2017].

Kurski, Jarosław (2002): Wrocław i Balkany [Breslau und Balkanen]. In: Gazeta Wyborcza, 16.05.2002, Nr. 113, 14.

Maciejewska, Beata (2002): Wrocław boi się Niemców [Breslau hat Angst vor Deutschen]. In: Gazeta Wyborcza, 17.05.2002, Nr. 114, 21.

Mecner, Filip (2003): Apel w sprawie Centrum przeciwko Wypędzeniom [Aufruf zum Zentrum gegen Vertreibungen]. In: Gazeta Wyborcza, 19.-20.07.2003, Nr. 167, 3; online unter: http://szukaj.wyborcza .pl/archiwum/1,0,2145999.html?kdl=20030719WRW\&wyr=Centrum+przeciwko+wyp\%EAdzeniom $+\& \mathrm{t}=1227386997381$ [Stand: 16.03.2017].

Michnik, Adam / Krzemiński, Adam (2002): Breslau, nicht Berlin. (Offener Brief an Bundeskanzler Gerhard Schröder und Premierminister Leszek Miller). In: Die Welt, 15.05.2002; online unter: http://www.welt.de /data/2002/05/15/418785.html [Stand: 16.03.2017].

Pięciak, Wojciech (2003): Naród ofiar. In: Rzeczpospolita, 02.08.2003; online unter: http://new-arch.rp.pl /artykul/445912.html [Stand: 14.03.2017].

Schily (1999) = Schily befürwortet Zentrum gegen Vertreibungen in Berlin. In: Frankfurter Allgemeine Zeitung, 31.05.1999, Nr. 123, 6.

Steinbach, Erika (1999): Das Gewissen ist gegen Vertreibungen sensibilisiert. Den Worten müssen Taten folgen. In: Süddeutsche Zeitung, 26.08.1999, Nr. 196, 11.

Stiftung (2009) = Stiftung „Flucht, Vertreibung, Versöhnung“: Polnischer Historiker will kein „Feigenblatt“ sein. In: Frankfurter Allgemeine Zetung, 16.12.2009; online unter:_http://www.faz.net/aktuell/politik/inland /stiftung-flucht-vertreibung-versoehnung-polnischer-historiker-will-kein-feigenblatt-sein-1901386.html [Stand: 30.03.2017].

Wonka, Dieter (2000): Vertriebene für Gedenkstätte neben Holocaust-Mahnmal. In: Leipziger Volkszeitung, 29.05.2000, 3 . 


\section{d) Internetquellen:}

Absichtserklärung (2005) = Absichtserklärung der Kulturminister Deutschlands, Polens, der Slowakei und Ungarns über die Gründung des Europäischen Netzwerks Erinnerung und Solidarität, Warschau, 2. Februar 2005; online unter: http://archiv.bundesregierung.de/bpaexport/artikel/33/782733/multi.html [16.03.20017].

Chwin, Stefan (2003): Das „Glück“ der Vertriebenen. In: Neue Zürcher Zeitung, 20.10.2003; online unter: http:// www.nzz.ch/2003/10/20/fe/article95P7B.html [Stand: 23.11.2009].

Eckpunkte (2010) = Eckpunkte für die Arbeit der Stiftung Flucht, Vertreibung, Versöhnung und die geplante Dauerausstellung; online unter: https://www.sfvv.de/sites/default/files/2010_10_25_eckpunkte_sfvv.pdf [Stand: 30.03.2018].

Gauck, Joachim (2016): Ansprache anlässlich des Tags der Heimat des Bundes der Vertriebenen im Humboldtsaal der Urania in Berlin, 03.09.2016; online unter: http://www.bundespraesident.de/SharedDocs/Reden /DE/Joachim-Gauck/Reden/2016/09/160903-Tag-der-Heimat.html [stand: 22.03.2018].

Gemeinsam für Deutschland (2005) = Gemeinsam für Deutschland. Mit Mut und Menschlichkeit. Koalitionsvertrag von CDU, CSU und SPD, Berlin, 11. November 2005; online unter: http://www.cdu.de/doc /pdf/05_11_11_Koalitionsver-trag.pdf [Stand: 30.03.20017].

Grundsatzerklärung (2003) = Grundsatzerklärung der Stiftung „Zentrum gegen Vertreibungen“, Wiesbaden, Sommer 2003; online unter: http://www.z-g-v.de/aktuelles/?id=35 [Stand: 14.03.2017].

\section{Tomasz Dziura}

Institut für Germanistik, Universität Wrocław

tom.dziura@gmail.com 